\title{
Federalismo e políticas municipais de financiamento à cultura no Brasil
}

\section{Antonio Albino Canelas Rubim ${ }^{1}$ \\ Juliana Almeida ${ }^{2}$ \\ Sofia Mettenheim ${ }^{3}$}

\begin{abstract}
Resumo: A estrutura federativa brasileira historicamente fortaleceu os entes locais, que possuem autonomia e competências relevantes - desafios frente à falta de recursos e capacidade institucional encontrada em grande parte dos municípios brasileiros. Com o crescente desmonte das políticas públicas de cultura no âmbito federal, e com os ataques em curso pelo governo ao campo cultural, os municípios se apresentam como pilar importante de execução de políticas culturais. Como tem sido desenvolvida a política de fomento à cultura nesse contexto? A partir dos dados disponíveis sobre a gestão municipal da cultura nas Pesquisas de Informações Básicas Municipais (MUNIC/IBGE), o artigo se debruça sobre 1) a institucionalidade das gestões municipais de cultura, buscando identificar quais estruturas e em quais condições a gestão local da cultura tem se realizado; e 2) as políticas de fomento à cultura que as gestões têm executado, com especial atenção aos segmentos apoiados e aos instrumentos utilizados. A partir dos dados, apontam-se modelos, tendências e hipóteses sobre as políticas de fomento à cultura municipais, entendendo a relevância de melhor compreendê-las em um momento que se colocam como importante possibilidade de democratização.
\end{abstract}

Palavras-chave: Federalismo; políticas culturais municipais; financiamento à cultura.

\section{Federalismo y Políticas culturales municipales en Brasil}

Resumen: La estructura federativa brasileña ha fortalecido históricamente a las entidades locales, que tienen autonomía y competencias en varios sectores - desafíos ante la falta de recursos y capacidad institucional que se encuentra en la mayoría de los municipios brasileños. Con el creciente desmantelamiento de las políticas culturales públicas a nivel federal, y con los continuos ataques del gobierno al sector de la cultura, los municipios se presentan como un pilar importante para la

\footnotetext{
${ }^{1}$ Antonio Albino Canelas Rubim. Doutor em Sociologia pela USP. Pesquisador do CNPq e do Centro de Estudos Multidisciplinares em Cultura (CULT). Professor do Programa Multidisciplinar de PósGraduação em Cultura e Sociedade da Universidade Federal da Bahia, Brasil. E-mail: albino.rubim@gmail.com - https://orcid.org/0000-0001-6953-7533

${ }^{2} J u l i a n a$ Almeida. Gestora cultural e mestranda no Programa Multidisciplinar de Pós-Graduação em Cultura e Sociedade da UFBA, Salvador, Brasil. E-mail: julisalmeida@gmail.com https://orcid.org/0000-0002-7013-3189

${ }^{3}$ Sofia Mettenheim. Administradora Pública e mestranda no Programa Multidisciplinar de PósGraduação em Cultura e Sociedade da UFBA, Salvador, Brasil. E-mail: sofiamettenheim@gmail.com https://orcid.org/0000-0002-7957-9929
} 
implementación de políticas culturales. ¿Cómo se ha desarrollado la política de promoción de la cultura en este contexto? Usando los datos disponibles sobre la gestión de la cultura municipal en la Investigación de Información Básica Municipal (MUNIC/IBGE), este artículo se centra en la institucionalidad de la gestión municipal de la cultura, buscando identificar qué estructuras y bajo qué condiciones se ha realizado la gestión local de la cultura; y las políticas para fomentar la cultura que las administraciones han implementado, con especial atención a los segmentos apoyados y los instrumentos utilizados. En base a los datos, se generan modelos, tendencias e hipótesis sobre las políticas culturales. La comprensión del impacto de estas medidas es especialmente relevante en este momento en el que se presenta una posibilidad importante para la democratización de la cultura.

Palabras clave: Federalismo; políticas culturales municipales; financiación de la cultura.

\title{
Federalism and municipal cultural promotion policy in Brazil
}

\begin{abstract}
Historically, the Brazilian federal structure has granted municipalities with significant autonomy and responsibilities. This provides challenges given the lack of resources and institutional capacities that characterize local governments. However, given the dismantlement of cultural policy at the federal level and successive attacks on cultural production itself, local governments have none the less emerged as important pillars to guarantee the implementation of cultural policy. How have public policies of cultural promotion evolved in this context? This article uses data on the municipal management of culture available in the "Pesquisas de Informações Básicas Municipais" (Basic Municipal Information Research, MUNIC/IBGE) to analyze 1) the institutional context of public cultural management at the municipal level to identify the factors behind the implementation of cultural policy and 2) the types of cultural promotion policies implemented, with special attention to the cultural area and methods of public administration utilized. The identification of tendencies, models, and hypotheses about cultural promotion at the municipal level provide better understanding of these policies at a moment when local governments represent important opportunities for democratization.
\end{abstract}

Keywords: Federalism; cultural policy; local government; cultural promotion.

\section{Federalismo e políticas municipais de financiamento à cultura no Brasil}

O conflituoso enfrentamento do

coronavírus no Brasil colocou em

evidência que o país tem uma

estrutura organizacional federativa. $O$

embate envolvendo a gestão da União, que considerava a COVID apenas uma gripe sem necessidade de maiores cuidados sanitários, e muitos estados

e diversos municípios, preocupados com a pandemia e que adotaram as medidas preconizadas pela Organização Mundial de Saúde (OMS), demonstrou que na federação brasileira existem poderes descentralizados atribuídos aos entes federativos pela Constituição Federal de 1988. O exercício da estrutura federativa impediu que a tragédia sanitária no Brasil alcançasse números ainda terríveis, devido à completa irresponsabilidade do governo federal de Messias Bolsonaro. 


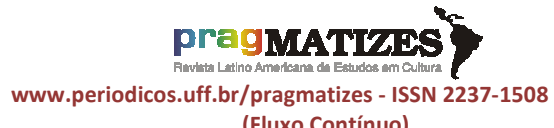

(Fluxo Contínuo)
Diferente da Colômbia, um país de organização unitária, o Brasil desde a proclamação da República (1889) e da primeira constituição republicana (1891) possui uma estrutura federativa (CUNHA FILHO; RIBEIRO, 2013, p. 26). A longa história da federação não tem assegurado a sua efetivação de maneira satisfatória. Poucos exemplos existem ainda hoje de exercício qualificado da organização federativa. O Sistema Único de Saúde (SUS), hoje profundamente ameaçado pela drástica redução orçamentária e pela militarização do Ministério da Saúde, aparece como um dos melhores exemplos de trabalho harmônico e colaborativo entre todos os entes federativos. A distinção de responsabilidades no âmbito da Educação configura outro bom exemplo de funcionamento da federação brasileira, com nítida distribuição complementar de competências entre os entes federativos: ensino superior, sob incumbência da União; ensino médio, atribuído aos Estados e ensino primário, subordinado aos Municípios.

A federação vem tendo seu desenvolvimento interditado pela concentração de poderes na União, própria dos largos períodos autoritários, ditadura do Estado Novo (1937-1945) e ditadura civil-militar (1964-1985), e pela tendência de centralização do estado nacional, que ocorre mesmo em períodos ditos democráticos. Tal tendência funciona sempre na contramão do desenvolvimento da federação, que requer o exercício mais equilibrado de responsabilidades entre os entes federativos. Em visível contraste com esta tendência de fortalecimento da União, em alguns instantes históricos foram ampliadas as competências dos outros entes federativos. Até 1988, a federação era apenas constituída de União e Estados. A partir da Constituição daquele ano a federação passou a ser composta por União, Estados, Distrito Federal e Municípios (CUNHA FILHO; RIBEIRO, 2013, p. 34). $\mathrm{Na}$ atualidade, a República Federativa do Brasil abrange: União, Distrito Federal, 26 Estados e 5.570 municípios, adquirindo singular complexidade, posto que a grande maioria dos países federados existentes no mundo abrange apenas União e Estados.

Os entes federativos previstos pela Constituição Federal de 1988 
RUBIM, Antonio Albino C.; ALMEIDA, Juliana; METTENHEIM, Sofia. Federalismo e políticas municipais de financiamento à cultura no Brasil. PragMATIZES - Revista Latino-Americana de Estudos em Cultura, Niterói/RJ, Ano 11, n. 20, p. 300-326, março 2021.

possuem um conjunto amplo de direitos e deveres. Eles têm legislações específicas para definir sua estrutura institucional, submetidas à carta constitucional nacional. Nesta perspectiva, os estados possuem constituições estaduais e os municípios leis orgânicas. Estados e municípios podem cobrar determinados impostos e taxas, além de receberem repasses financeiros obrigatórios da União para Estados e Municípios e do Estado para os Municípios. Eles podem elaborar leis e assumir tarefas executivas no âmbito estadual ou municipal. Ou seja, são assegurados pela Constituição Federal aos entes federativos, pelo menos formalmente, direitos que viabilizam certa autonomia de gestão e de implementação de políticas, ainda que subordinadas aos parâmetros existentes na carta constitucional federal. Como as delimitações nem sempre são cristalinas, elas terminam gerando algumas zonas de tensão entre os entes federativos.

As novas competências atribuídas aos entes municipais pela Constituição Federal de 1988 trouxeram mais autonomia, mas responsabilizaram os governos locais

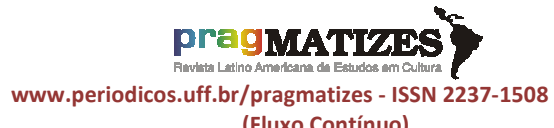

(Fluxo Contínuo)

pela resolução de problemas sociais complexos. Frente a esses desafios, os municípios foram responsáveis por um ciclo de inovação nas políticas públicas brasileiras, constituindo uma "inflexão marcada pela emergência de inovações no nível local nas últimas décadas" (FARAH, 2006, p. 71). Não são poucas as políticas públicas federais hoje em vigor cuja origem remonta a experiências municipais. Para ficar com alguns exemplos, o pilar das políticas sociais federais, 0 "Programa Bolsa-Família", teve seu desenho elaborado a partir de diferentes políticas de âmbito municipal $^{4}$. Do mesmo modo, a principal estratégia federal de atenção básica à saúde, o "Programa Saúde da Família", estruturante na construção do SUS, se efetivou a partir de experiências de programas comunitários e de atenção básica de uma série de municípios brasileiros ${ }^{5}$.

\footnotetext{
${ }^{4}$ Desde os anos 1990 iniciaram-se no Brasil experiências municipais de programas de transferência de renda, como o Programa de Garantia de Renda Familiar Mínima, em Campinas; o Programa Bolsa Familiar para a Educação (Bolsa Escola); o Programa de Garantia de Renda Familiar Mínima, em Ribeirão Preto e o Programa "Nossa Família" em Santos (Silva; Giovanni; Yasbeck, 2008).

${ }^{5}$ Da mesma forma, o Programa Saúde da Família, que nasce em âmbito federal, surge como uma proposta ousada para a reestruturação do sistema de saúde,
} 
Junto ao processo de desmonte institucional das políticas sociais que ocorre no âmbito federal desde o golpe de 2016, ambas as políticas federais têm tido sua importância escancarada na crise decorrente da COVID-19 e ressaltado o papel dos governos locais no fortalecimento das redes de cuidado nos territórios.

Para além do caráter inovador e da relação com o território, peculiar a essa instância de governo, características imanentes ao atual mundo globalizado permitem ampliar a autonomia relativa de Estados e Municípios. Hoje, ambos podem exercer atividades até hoje formalmente restritas ao governo da União, como relações externas internacionais. Muitos Estados e diversos Municípios dispõem, a depender da dimensão, de assessorias ou de secretarias de relações internacionais. Os Estados e os municípios/cidades mantêm intercâmbio e trocas, inclusive culturais, no mundo contemporâneo. Caso similar ocorre em relação aos

organizando a atenção primária e substituindo os modelos tradicionais existentes. Porto Alegre, São Paulo, Niterói, Recife, Cotia/SP, Planaltina/GO e Mambaí/GO inspiraram a construir os princípios do PSF (Pinto e Giovanella, 2018). modelos de desenvolvimento. Antes adstritos ao governo da União, eles agora podem ser implantados, em horizonte complementar, por Estados, por Municípios e mesmo por consórcios interestaduais e intermunicipais, sob o formato de planos de desenvolvimento regionais, estaduais e municipais ou locais. Estas novas circunstâncias societárias (RUBIM, 2001) abrem possibilidades de ampliação da autonomia relativa dos Estados e Municípios, que se exercem ou não a depender de diferentes fatores.

$\mathrm{Na}$ gestão municipal da cultura não é diferente: os governos locais ocupam relevante papel na geração de políticas culturais inovadoras e desfrutam de boas possibilidades de autonomia. A gestão pioneira do escritor Mário de Andrade no Departamento de Cultura da Prefeitura de São Paulo (1935-1938) é um bom exemplo. $\mathrm{O}$ intelectual modernista inovou em intervir de forma sistemática no campo, propor uma dimensão ampla da noção de cultura (além das belas-artes), reconhecer o patrimônio material e imaterial produzidos pelos diversos segmentos da sociedade. Outro marco de sua gestão foi o 
patrocínio de missões etnográficas às regiões amazônica e nordestina, valorizando os acervos culturais produzidos fora do eixo dinâmico do país (RUBIM, 2007).

Além desse exemplo icônico, Márcio Meira (2016) chama a atenção para a importância das gestões locais na construção do ciclo de políticas culturais federais democráticas, entre os anos de 2003 e 2015. O autor destaca que, desde os anos 1980, as experiências locais trazem novos conceitos e práticas que se constituíram como referências no campo das políticas culturais. É o caso da "Política de Cidadania Cultural" proposta pela filósofa Marilena Chauí, na Secretaria Municipal de Cultura de São Paulo, na administração de Luiza Erundina (1989-1993). Outros exemplos são as experiências participativas vividas por gestões municipais de Porto Alegre, Belo Horizonte, Belém, Recife, Rio Branco, Campinas, Londrina, entre outras (MEIRA, 2016, p. 18-22). Reconhecer o papel dessas políticas aponta para a relevância histórica das gestões locais, mas também para sua relevância na construção das políticas culturais democráticas, em especial em momentos de autoritarismo e desmonte das políticas culturais federais, como ocorre na atualidade brasileira.

Todo este quadro de possibilidades encontra inúmeras dificuldades de ser implementado. A maior delas é a concentração do orçamento em mãos da União e de modo subsidiário nos Estados. Tal panorama dificulta, quando não inviabiliza, que a autonomia relativa dos municípios, amparada na Carta Federal e nas características da contemporaneidade, seja exercitada de modo efetivamente federativo. contexto se agrava ainda mais quando se observa que a imensa maioria $(68,3 \%)$ dos municípios brasileiros é formada por pequenas localidades de até 20 mil habitantes, em geral com reduzida dinâmica socioeconômica e parcos recursos próprios. Assim, majoritariamente os municípios brasileiros dependem financeiramente de verbas da União, principalmente, e dos Estados,em segundo plano. Diante da insistente carência de recursos muitas das potencialidades de autonomia relativa dos municípios em definir suas políticas quase deixam de existir. Os dilemas de República 


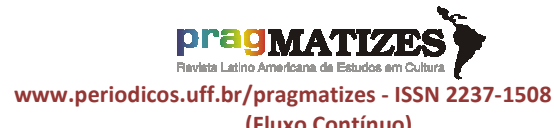

(Fluxo Contínuo)
Federativa do Brasil tornam-se gigantescos para sua realização enquanto verdadeira federação.

Só bem recentemente a perspectiva federativa tem sido discutida no campo das políticas culturais. A gestão de Gilberto Gil no Ministério da Cultura (2003-2008), entre muitas das suas inovações, atualizou a gestão pública da cultura ao introduzir esta dimensão. Essas inovações, entretanto, não conseguiram ser assumidas plenamente, perpassando todo trabalho do Ministério. Alexandre Barbalho, José Márcio Barros e Lia Calabre observam que as Conferências Nacionais de Cultura (CNC), o Plano Nacional de Cultura (PNC) e, principalmente, o Sistema Nacional de Cultura (SNC) "tinham claramente o objetivo de estabelecer 0 federalismo cultural". Já outras iniciativas "acabaram por estabelecer uma forte relação entre as esferas: federal, estadual e municipal, como os Pontos de Cultura" (BARBALHO; BARROS; CALABRE, 2013, p. 9). Talvez os autores não tenham querido dizer que o Programa Cultura Viva ${ }^{6}$,

\footnotetext{
${ }^{6}$ Cultura Viva é um programa do governo federal brasileiro, criado em 2004, que tem
}

um dos mais emblemáticos do Ministério, apesar das relevantes conexões viabilizadas, não se pautou por uma lógica federativa. O recurso à atuação de estados e municípios no programa decorreu muito mais das dificuldades de gerenciamento do Ministério, que da busca consistente de gestão federativa compartilhada do Cultura Viva.

Como bem assinalam os três autores, as conferências e os planos nacionais de cultura já eram atravessados por um olhar federativo no desenvolvimento das políticas culturais. Mas a perspectiva federativa se aprimorou e consolidou no processo de elaboração do SNC. Apesar de existirem percepções diferenciadas sobre a presença do federalismo nas primeiras formulações do SNC, a visão prevalecente aponta para uma relativa ausência nos primórdios da concepção do SNC. Roberto Peixe diz que: "o sistema não

como carro chefe a criação dos Pontos de Cultura. Em 2014, passou a ser uma Política de Estado, com a sanção da Lei 13.018 que institui a Política Nacional de Cultura Viva. Trata-se de uma política eminentemente de base comunitária que visa o amplo exercício dos direitos culturais pelo conjunto da população brasileira, explorando as potencialidades da cultura como eixo transversal do desenvolvimento social e econômico sustentável. 
RUBIM, Antonio Albino C.; ALMEIDA, Juliana; METTENHEIM, Sofia. Federalismo e políticas municipais de financiamento à cultura no Brasil. PragMATIZES - Revista Latino-Americana de Estudos em Cultura, Niterói/RJ, Ano 11, n. 20, p. 300-326, março 2021.

nasceu com essa visão clara federativa" (PEIXE apud ROCHA, 2018, p. 78). Bernardo Mata Machado concorda com tal entendimento. Para ele a perspectiva federalista não estava em foco no início do SNC, pois a preocupação era a retomada do papel do poder público nas políticas culturais. Ele afirma: "A gente não tinha muito na cabeça a questão federativa". (MACHADO apud ROCHA, 2018, p. 78). Desta maneira, o processo de constituição do SNC aprofundou continuadamente seu federalismo cultural, que passou a marcar o SNC. Sophia Rocha, na sua tese de doutorado, acompanha cuidadosamente passos e percalços dessa complexa tessitura, mesmo dentro do próprio ministério (ROCHA, 2018).

O SNC implicava na existência de componentes articulados em níveis federal, estaduais e municipais, tais como: órgãos gestores de cultura, conselhos, conferências, comissões intergestoras, conselhos, planos, sistemas de financiamento à cultura, sistemas de informações e indicadores culturais, programas de formação na área da cultura e sistemas setoriais de cultura articulados (MINISTÉRIO DA

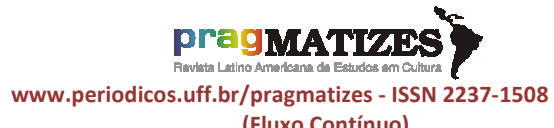

(Fluxo Contínuo)

CULTURA, 2011). O SNC acolheu, como nenhuma outra iniciativa do Ministério, um horizonte militante nitidamente federalista. Ele estimulou inovadora reflexão sobre os enlaces entre cultura e federalismo. Muitas análises sobre a temática floresceram em diálogo com o SNC.

Os interessantes avanços federalistas propiciados pelo SNC não resolveram, no entanto, alguns aspectos vitais para 0 desenvolvimento do federalismo cultural. Não se conseguiu acordar uma delimitação de competências dos entes federativos na esfera da cultura. Rodrigo Costa, por exemplo, na análise que realiza sobre o tema do patrimônio cultural, afirma que todos os entes federativos podem ter políticas patrimoniais, apenas limitadas no referente aos direitos autorais e à propriedade de sítios arqueológicos e pré-históricos, áreas exclusivas de atuação da União (COSTA, 2011, p. 48, 49). Deste modo, todos os entes federativos podem atuar, de modo complementar ou mesmo concorrente, em quase todos os ambientes culturais, inclusive no financiamento à cultura, tema de reflexão deste texto. Cabe ressaltar que os Estados e, em 
RUBIM, Antonio Albino C.; ALMEIDA, Juliana; METTENHEIM, Sofia. Federalismo e políticas municipais de financiamento à cultura no Brasil. PragMATIZES - Revista Latino-Americana de Estudos em Cultura, Niterói/RJ, Ano 11, n. 20, p. 300-326, março 2021.

especial, os Municípios, em muitos casos, parecem não ter plena consciência das potencialidades de sua autonomia federativa.

A situação vivida hoje no Brasil impõe enormes retrocessos ao desenvolvimento do país em uma perspectiva federalista. A tentação autoritária do atual governo busca concentrar poder na União, em detrimento de Estados e Municípios, ferindo o pacto federativo, previsto na Constituição Federal. A circunstância se agrava quando se observam as atitudes da gestão federal em relação à cultura: destruiu o Ministério da Cultura e em seu lugar tornou a cultura uma mera secretaria, vinculada primeiro ao Ministério da Cidadania e depois ao Ministério do Turismo. Desde janeiro de 2019, quando começou o mandato de Messias Bolsonaro, cinco dirigentes já passaram pela Secretaria de Cultura. As políticas e os programas construídos nos governos dos presidentes Luiz Inácio Lula da Silva e Dilma Rousseff estão sendo desmontados. Além de implantar a censura e atacar as liberdades de criação e expressão, a gestão Messias Bolsonaro asfixia financeiramente 0

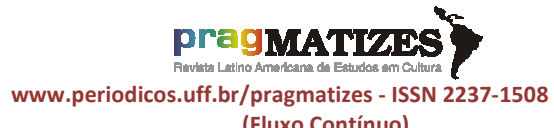

(Fluxo Contínuo)

campo cultural. Em resumo, o governo federal se mostra inimigo da cultura e do federalismo cultural no Brasil atual (RUBIM, 2020).

\section{Fomento à cultura no Brasil}

O campo do fomento à cultura no Brasil foi definido pelo protagonismo da Lei Federal de Incentivo à Cultura, Lei $\mathrm{n}^{\circ} 8.313$ de 23 de dezembro de 1991, que instituiu o Programa Nacional de Apoio à Cultura (Pronac). Fomento é um "[...] programa organizado, com normas e rotinas, de apoio e incentivo à cultura, que pode tornar diferentes formatos: créditos, fundos, incentivo fiscal etc." (ROCHA; FERNANDES, 2017, p. 20).Na origem, a Lei foi formulada como um sistema com três frentes de atuação: concessão de incentivos fiscais a empresas e indivíduos, que apoiassem projetos culturais; financiamento direto de iniciativas com menor visibilidade e capacidade de se auto sustentar, com o Fundo Nacional de Cultura (FNC); e por créditos provenientes de fundo de investimento a projetos rentáveis de empresas e produtoras (Ficart). Com as modificações feitas ao longo dos anos 1990, a referida Lei passou a ser dominada por lógicas neoliberais, 
privilegiando produções de caráter mais comercial e a concessão de benefícios fiscais cada vez maiores às empresas, ditas patrocinadoras.

Assim, a Lei, que prometia um sistema diversificado de fomento ao setor, se distorceu e o incentivo fiscal se tornou a forma predominante e quase única de fomento à cultura no Brasil. A empresa "patrocinadora" ganha em visibilidade, relacionamento com seus públicos e reputação de sua marca por meio do uso dos recursos quase completamente públicos. Em 1993, cerca de $70 \%$ dos recursos mobilizados pelo incentivo fiscal eram privados. Já em 2016, esse percentual foi reduzido para apenas 2,95\% (PAIVA NETO, 2017, p. 40-41). Com todas essas escandalosas vantagens concedidas ao setor privado, a Lei Federal de Incentivo à Cultura é, hoje, responsável pelo aporte anual de mais de um bilhão de reais (algo em torno de 200 milhões de dólares). Muitos estudos (RUBIM, 2007; OLIVIERI, 2004; SARKOVAS, 2005), já revelaram os desvios provocados pelas alterações da lei.

Cabe registrar, outro de seus aspectos que tem interesse para esse texto: a concentração regional. Em
2015, por exemplo, $79 \%$ dos recursos captados por meio da lei foram destinados a organizações e/ou indivíduos situados na região Sudeste, notadamente nos estados e nas cidades do São Paulo e Rio de Janeiro (PAIVA NETO, 2017). O sistema, pensado para atender a diferentes dinâmicas do setor cultural, com o passar dos anos, resumiu-se a viabilizar produções de grande porte, quase sempre de apelo mercantil, oriundas do eixo econômico do país, desprezando a diversidade do campo cultural e do próprio território brasileiro.

Apesar das discussões já empreendidas sobre o tema, nenhuma das tentativas de revisão mais profunda avançou. Uma evidência disso é que tramita no Congresso Nacional, desde 2010, projeto de reformulação da referida lei. Nem mesmo o FNC, um dos mecanismos previstos no seu texto, voltado às iniciativas culturais de caráter não comercial, teve um uso mais potente e longevo. Carlos Paiva Neto (2017) mostrou que os recursos do Fundo cresceram em patamares muito inferiores aos do incentivo fiscal. Além dos sucessivos contingenciamentos que o FNC vem sofrendo nos últimos 
RUBIM, Antonio Albino C.; ALMEIDA, Juliana; METTENHEIM, Sofia. Federalismo e políticas municipais de financiamento à cultura no Brasil. PragMATIZES - Revista Latino-Americana de Estudos em Cultura, Niterói/RJ, Ano 11, n. 20, p. 300-326, março 2021.

anos, seu regramento não garante a destinação das verbas públicas para a comunidade cultural, pois possibilita que o próprio Ministério utilize esses recursos em seus programas institucionais. Deste modo, os parcos investimentos voltados ao dispositivo, tanto em termos de recursos financeiros, quanto de aprimoramento da gestão, resultaram em uma progressiva incapacidade do governo federal em lidar com as crescentes demandas setoriais e regionais da cultura.

Apesar das distorções, é preciso reconhecer que 0 incentivo fiscal foi responsável pela sustentabilidade de grandes instituições culturais do país, como os museus, orquestras e teatros. Desconsiderando o trabalho de revisão crítica da lei empreendido no período anterior, com mobilização importante do setor cultural buscando democratizar o acesso aos recursos, em 2019 foi realizada uma série de alterações na sua estrutura por meio de Instrução Normativa. Dentre elas, previu-se uma drástica redução dos limites orçamentários dos projetos apoiados através do incentivo fiscal, impactando a dinâmica de

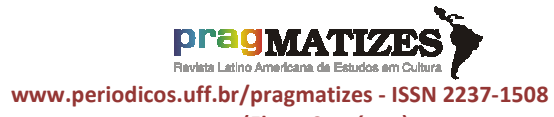

(Fluxo Contínuo)

funcionamento das grandes instituições culturais do país. Em paralelo, foi definido como diretriz que empresas públicas, importantes financiadoras do setor cultural no país, deixassem de utilizar a legislação. Ainda mais grave, são os casos explícitos de censura a conteúdos que valorizem a diversidade cultural e de gênero. Os casos de maior repercussão nacional foram a proibição por Messias Bolsonaro da campanha publicitária do Banco do Brasil que exaltava a diversidade racial e de gênero, assim como o sistema de censura prévia adotado pela Caixa Econômica no financiamento dos projetos culturais. Tais estratégias compõem parte do cenário de desmonte das políticas culturais pelo governo federal.

Frente à falência da política cultural federal, as iniciativas municipais de fomento ganham importância. Mesmo antes do agravamento da crise, o investimento do âmbito municipal já se destacava em relação aos demais entes federativos.

A pesquisa "Financiamento e Fomento à Cultura no Brasil: Estados e Distrito Federal", realizada com base nas execuções 
RUBIM, Antonio Albino C.; ALMEIDA, Juliana; METTENHEIM, Sofia. Federalismo e políticas municipais de financiamento à cultura no Brasil. PragMATIZES - Revista Latino-Americana de Estudos em Cultura, Niterói/RJ, Ano 11, n. 20, p. 300-326, março 2021.

orçamentárias dos anos de 2014 e 2015, mostrou que a União, apesar de ter gastos nominalmente maiores, empregou apenas $0,08 \%$ de seus recursos em cultura. Os estados e Distrito Federal aplicaram $0,41 \%$ em 2014 e 0,33\% em 2015. Já os municípios foram o ente federativo que mais investiu em cultura: no primeiro ano, $1,02 \%$ dos seus orçamentos, e, no ano seguinte, $0,91 \%$. Os gastos de todos os municípios alcançam $51 \%$ de todo investimento público direto em cultura no Brasil (RUBIM; PAIVA NETO, 2017). Os autores ainda confirmam que, "além de destinar as maiores fatias percentuais de recursos para a cultura, os municípios realizam o maior investimento per capita em cultura no âmbito de todos os entes federativos (RUBIM; PAIVA NETO, 2017, p. 101).

A importância das políticas municipais, que já se destacava em termos orçamentários, tende a crescer em meio à conjuntura política e econômica tão nefasta ao campo cultural. Essa tendência foi evidenciada na articulação das gestões locais e estaduais na mobilização em torno da Lei no 14.017 , de 29 de junho de 2020, intitulada Aldir

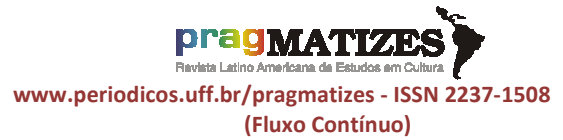

Blanc, que busca garantir recursos para ações emergenciais de apoio ao setor cultural. A mobilização aposta nas demais instâncias federativas, frente à absoluta inação do governo federal em relação ao enfrentamento da COVID-19. A Lei, de iniciativa de representantes do poder legislativo federal, contou com ampla mobilização do setor cultural, que se valeu de todas as possibilidades de militância nos ambientes digitais. O marco legal foi aprovado prevendo: o pagamento de um pequeno auxílio por três meses para artistas informais; subsídio para manutenção de micro e pequenas empresas e demais organizações comunitárias culturais e também de espaços artísticos; além da realização de ações de incentivo à produção cultural, como a realização de cursos, editais, prêmios. Os recursos, provenientes do FNC, devem ser transferidos da União para serem executados por estados, Distrito Federal e municípios. Com a conquista dos recursos, os entes federativos podem realizar uma política cultural emergencial para a sobrevivência do setor cultural, desamparado pelas políticas federais. 
RUBIM, Antonio Albino C.; ALMEIDA, Juliana; METTENHEIM, Sofia. Federalismo e políticas municipais de financiamento à cultura no Brasil. PragMATIZES - Revista Latino-Americana de Estudos em Cultura, Niterói/RJ, Ano 11, n. 20, p. 300-326, março 2021.

Apesar dessa crescente atuação, conhece-se pouco o cenário das iniciativas municipais. Na pesquisa "Financiamento e Fomento à Cultura no Brasil: Estados e Distrito Federal", citada anteriormente, foi realizado um mapeamento dos estudos de fomento no Brasil e foi revelado que apenas $12 \%$ deles são voltados para programas municipais (GUIMARÃES; SILVA, 2017, p. 74). No que se refere à produção de estatísticas, a lacuna parece se aprofundar, pois o desafio é duplo: há no país um déficit de produção de dados e indicadores tanto no campo das políticas culturais, quanto no âmbito da gestão pública local. Importante exceção a essa regra é a "Pesquisa de Informações Básicas Municipais (MUNIC)", que passou a incluir, desde 2004, em uma parceria com o então Ministério da Cultura, um levantamento robusto de dados sobre a gestão cultural municipal. Apesar de relevância, a MUNIC apresenta uma dificuldade que pode afetar suas informações: as fontes são os próprios gestores municipais, o que possibilita que dados específicos sofram alguma distorção. Tal limitação não afeta, no entanto, o uso de seus dados para análises mais amplas sobre

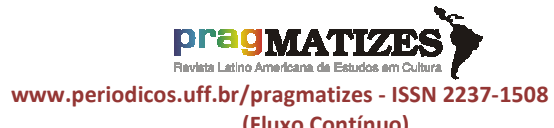

(Fluxo Contínuo)

tendências das intervenções na cultura.

Para Paiva Neto (2017, p. 15) essa lacuna se dá, dentre muitos motivos, pela visibilidade das políticas federais, uma vez que a União "possui a maior estrutura administrativa; gerencia o maior orçamento; é titular de algumas responsabilidades exclusivas; suas políticas têm alcance em todo território". No entanto, como vimos, a instância municipal é a que mais investe no setor. Nesse contexto, as experiências das cidades médias e grandes cidades são as que se destacam, com políticas culturais mais complexas e de maior alcance.

Considerando as diferenças e disparidades destacadas do âmbito municipal no contexto brasileiro, um desafio que se coloca é compreender como os municípios têm se engajado para cumprir seus papéis e responsabilidades como entes da federação brasileira. Como as gestões públicas municipais podem salvaguardar e promover a diversidade cultural que se revela em seus territórios? Que instrumentos, práticas e métodos da gestão pública da cultura podem ser referências na gestão local da cultura em municípios 
de tão diferentes portes e complexidades sociais, econômicas e territoriais? Para alcançar o desejo que o fomento à cultura seja pensado de maneira tão complexa quanto o fazer cultural (RUBIM, 2016), é imprescindível mergulhar mais fundo nas alternativas e soluções criadas pelos diferentes atores da gestão pública da cultura.

\section{Fomento à cultura nos municípios: modelos possíveis}

Para apontar alguns modelos, tendências e hipóteses sobre as políticas municipais de fomento à cultura, utilizam-se dados extraídos das MUNIC's dos anos de 2014 e 2018 (IBGE, 2015 e 2019) ${ }^{7}$. Dentre as diversas possibilidades de análise da pesquisa, dois aspectos interessam: 1. A institucionalidade das gestões municipais de cultura, buscando identificar quais estruturas e em quais condições a gestão local da cultura tem se realizado; e 2. As políticas de fomento à cultura que as gestões têm executado, com especial atenção aos

\footnotetext{
${ }^{7} \mathrm{Na}$ MUNIC de 2014 foi publicado um suplemento específico para a cultura. Já na pesquisa de 2018 foi apresentado um estudo mais resumido, inserindo apenas alguns eixos de análise do questionário completo.
}

segmentos apoiados e aos instrumentos utilizados.

Uma primeira pergunta parece anteceder a análise: que municípios no Brasil consideram possuir uma "política cultural"? A primeira resposta é nem todos, pois $45,33 \%$ deles responderam não possuir uma política cultural. Esse percentual, que chega a $56,72 \%$ nos pequenos municípios (de até 5 mil habitantes), decresce gradativamente até chegar a menos de $3 \%$ no caso dos municípios com mais de 500 mil (IBGE,2019). Apesar da resposta também variar entre as regiões $^{8}$ e entre os estados ${ }^{9}$, a disparidade em relação ao porte dos municípios é aquela que mais chama atenção, anunciando uma desigualdade que se fará presente ao longo dos demais resultados da pesquisa.

\footnotetext{
${ }^{8}$ Variando entre $55,25 \%$ (no Centro-Oeste) e $37,53 \%$ (no Sudeste) o percentual dos municípios que afirmam não possuir política municipal de cultura (IBGE, 2019).
${ }^{9}$ No caso das unidades federativas, o Estado com maior número de municípios, que afirmou não possuir política municipal de cultura, foi Tocantins (com $64,75 \%$ ), enquanto o menor foi o Rio de Janeiro, com $16,30 \%$ dos municípios (IBGE, 2019).




\section{Institucionalidade das}

\section{gestões municipais}

A caracterização do órgão gestor da cultura é importante, pois pode significar prestígio político e a autonomia deles nos governos locais. Ocorre um crescimento marcante de $4,3 \%$ (em 2006) para $20,4 \%$ (em 2014) dos municípios que possuem secretaria exclusiva de cultura, com respectivo decréscimo de secretarias que reúnem a cultura com outras áreas. Elas passam de 73,8\% (em 2006) para 57,3\% (em 2014), conforme dados do IBGE (2007 e 2015). Ainda que se reconheça o papel transversal da gestão da cultura, a existência de estruturas institucionais conjuntas significa, muitas vezes, a subalternização da política cultural perante outras políticas setoriais, como educação ou turismo. O crescimento de secretarias exclusivas nos municípios pode sinalizar uma maior valorização da cultura nas gestões locais.

Embora sem retornar aos patamares iniciais de 2006, o panorama se altera nos resultados de 2018: diminui o percentual de municípios com secretaria exclusiva (de 20,4\%, em 2014, para $15,2 \%$, em
2018), e aumenta o percentual de secretarias municipais em conjunto com outras políticas (de 57,3\%, em 2014, para 68,6\%, em 2018), em uma variação de mais de 10 pontos percentuais (IBGE, 2015 e 2019). O movimento pode ser reflexo da combinação entre crise econômica, que se agravou no país no período, e crise política, com o golpe midiáticojurídico-parlamentar, que depôs a presidenta Dilma Rousseff, e produziu graves retrocessos nas políticas culturais de âmbito nacional e teve brutal repercussão sobre Estados e Municípios.

A disparidade institucional da gestão cultural local também decorre do porte populacional dos municípios. Enquanto nos municípios com mais 500 mil habitantes o percentual com presença de secretarias exclusivas chega a 48,72\%, nos municípios menores, com até 5 mil habitantes, o número é de 20,38\%. Outras fragilidades institucionais da gestão da cultura igualmente se fazem presentes nos pequenos municípios: o percentual deles que não possui estrutura de gestão da cultura chega a $9,81 \%$ e o percentual que possui 0 setor subordinado diretamente à chefia do 
RUBIM, Antonio Albino C.; ALMEIDA, Juliana; METTENHEIM, Sofia. Federalismo e políticas municipais de financiamento à cultura no Brasil. PragMATIZES - Revista Latino-Americana de Estudos em Cultura, Niterói/RJ, Ano 11, n. 20, p. 300-326, março 2021.

executivo é de 5,65\% (IBGE, 2019). Essa última modalidade, apesar de reservar à gestão da cultura uma posição que poderia ser considerada estratégica politicamente, na prática se transforma em "área produtora de eventos que beneficiem a imagem da gestão em pauta" (IBGE, 2015), sem espaço para efetivação de políticas culturais mais estruturadas e democráticas.

Os dados sobre o órgão gestor local da cultura informam também a precariedade existente em termos de estrutura administrativa e de pessoal. Ainda que não caiba neste texto a análise de tais pormenores, o registro de algumas situações pode trazer revelações para 0 estudo. Nos municípios com menos de 100 mil habitantes $(94,61 \%$ dos municípios brasileiros) $\quad 22,81 \%$ dos órgãos gestores de cultura não possuem linha telefônica, nem ramal, e 11,3\% não possuem nenhum computador em funcionamento (IBGE, 2019). Como pensar políticas culturais que considerem a inclusão tecnológica, por exemplo, sem a informatização dos próprios órgãos gestores da cultura? Como pensar a transparência e

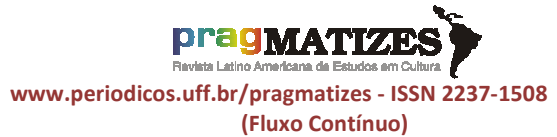

participação sem canais de comunicação?

Outros dados relevantes se referem às instâncias de gestão e participação municipais, que ajudam a compreender como as gestões locais se organizam e a partir de que modelos executam suas políticas. Um importante instrumento norteador da política cultural, por exemplo, é o Plano Municipal de Cultura, existente em $11,75 \%$ dos municípios e em elaboração em outros 17,47\%. (IBGE, 2019). No que se refere às instâncias participativas, o grande boom de criação de conselhos se dá em 2005, auge das mobilizações em torno do SNC, chegando a $17 \%$ no ano de 2006 (IBGE, 2007). Ao longo dos anos, os conselhos parecem se consolidar como importante instância na gestão cultural local do país, chegando a existir em 42,23\% dos municípios em 2018 (IBGE, 2019). Cabe lembrar, entretanto, que a existência de planos e conselhos municipais de cultura não significa que eles funcionem de modo pleno ou mesmo sejam democráticos.

Considerando que os conselhos, planos e a existência do órgão gestor a nível municipal são contrapartidas para a adesão ao SNC, 
RUBIM, Antonio Albino C.; ALMEIDA, Juliana; METTENHEIM, Sofia. Federalismo e políticas municipais de financiamento à cultura no Brasil. PragMATIZES - Revista Latino-Americana de Estudos em Cultura, Niterói/RJ, Ano 11, n. 20, p. 300-326, março 2021.

0 processo

de

maior institucionalização verificado pode ser atribuído, pelo menos em parte, aos esforços do governo federal de impulsionar a valorização da gestão cultural no âmbito local. Assim, como se apontou, ainda que o SNC não tenha consolidado uma estrutura federativa na área cultural, ele serviu como um forte estímulo para o fortalecimento da gestão pública cultural municipal, impactando positivamente na sua institucionalização, seja pela energização dos debates sobre gestão cultural em todo o território nacional, pela valorização política que o tema desfrutou ou ainda pelas contrapartidas exigidas para a integração dos municípios ao SNC. As gestões nacionais posteriores ao golpe de 2016 fragilizaram imensamente 0 campo da cultura provocando vários rebatimentos na sua institucionalidade, inclusive nos demais entes federativos. O PNC, que deveria ser renovado em 2020, foi engavetado e o SNC paralisado, dentre outros retrocessos. O desmonte das políticas culturais efetuado de modo sistemático pela gestão Messias Bolsonaro, desde o início do mandato em 2019, impacta

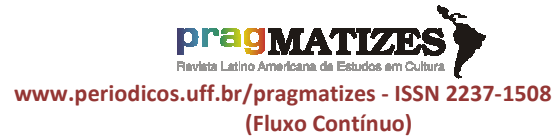

de modo profundamente negativo a gestão municipal de cultura no país.

\section{Fomento nas gestões locais:} modelos, mecanismos e atividades apoiadas

Um primeiro aspecto a ser estudado se refere aos diferentes modelos de execução de recursos. Como no âmbito federal, a política de fomento pode ocorrer por meio de isenção fiscal; dos fundos de cultura ou pela execução direta pelo órgão gestor local. No caso de leis de incentivo fiscal municipal, o último dado disponível é de 2006. Ele aponta que apenas $3,9 \%$ dos municípios possuíam leis de incentivo fiscal e delas somente $2,9 \%$ foram utilizadas nos últimos dois anos (IBGE, 2007). Historicamente, a predominância quase completa do incentivo fiscal no plano nacional estimulou a criação nas demais instâncias federativas de marcos legais com muitas semelhanças ao modelo federal. A replicação do incentivo fiscal foi impulsionada nos anos 90. Mesmo reconhecendo essa tendência de alinhamento dos modelos de fomento, o descompasso da utilização do incentivo fiscal entre a gestão 
RUBIM, Antonio Albino C.; ALMEIDA, Juliana; METTENHEIM, Sofia. Federalismo e políticas municipais de financiamento à cultura no Brasil. PragMATIZES - Revista Latino-Americana de Estudos em Cultura, Niterói/RJ, Ano 11, n. 20, p. 300-326, março 2021.

municipal e as gestões estaduais e, principalmente, a federal apresenta-se como notável.

A disparidade do percentual de municípios que afirma possuir leis dessa modalidade varia de modo muito acentuado a depender da dimensão do município: passa de meros $1,3 \%$ nos municípios com até cinco mil habitantes a $75 \%$ nos municípios com populações acima de 500 mil habitantes (IBGE, 2007). A enorme discrepância torna visível que o modelo do incentivo fiscal depende de inúmeros fatores, em especial da existência de arrecadação própria por parte do município. O incentivo fiscal mostra-se inviável em municípios menores, que dependem de repasses federativos para sobreviver. Mesmo em municípios de porte médio, tornase um desafio a adesão dos empresários locais ao mecanismo. As grandes empresas, muitas delas multinacionais, com departamentos especializados de marketing em investimentos culturais, se localizam e tendem a concentrar suas ações nas grandes cidades e nas principais capitais estaduais. Em consequência, o incentivo fiscal tem vigência restrita no âmbito municipal.

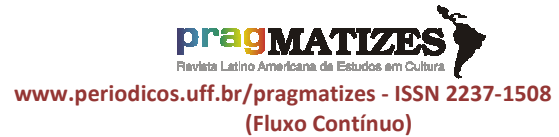

No caso dos fundos de cultura, os dados apontam um crescimento relevante da presença nos municípios: de 5,1\% em 2006 (IBGE, 2007) para 32,24\% em 2018 (IBGE, 2019). A distribuição de acordo com porte populacional segue tendência similar à do incentivo fiscal. Mas dados recentes indicam uma presença significativa de fundos de cultura mesmo em municípios menores, com menos de cinco mil habitantes: $22,35 \%$ informaram que possuíam tal mecanismo de fomento. Ou seja, o fundo está presente mesmo em municípios com baixa institucionalidade cultural (IBGE, 2019).

Um aspecto relevante para entender a atuação político-cultural dos municípios é o tipo de atividade cultural fomentada pelas gestões locais. Vale observar as respostas dadas pelas gestões municipais acerca das ações culturais incentivadas no último ano. A atividade cultural mais apoiada pelas gestões municipais são as "festas, celebrações e manifestações tradicionais e populares" (85,5\%), seguida pelos "eventos" (75,7\%), e, em terceiro lugar, pela "apresentação musical” $(62,8 \%)$. 
RUBIM, Antonio Albino C.; ALMEIDA, Juliana; METTENHEIM, Sofia. Federalismo e políticas municipais de financiamento à cultura no Brasil. PragMATIZES - Revista Latino-Americana de Estudos em Cultura, Niterói/RJ, Ano 11, n. 20, p. 300-326, março 2021.

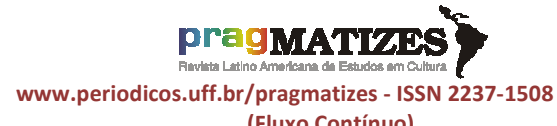

(Fluxo Contínuo)
Com percentuais menores, de aproximadamente $30 \%$, aparecem: "montagem de peças teatrais", "seminário, simpósio, encontro, congresso, palestra" e "desfile de carnaval". As demais categorias de atividades, como "publicações culturais", "feira de livros", "programa radiofônico" e "programa de televisão", possuem percentuais abaixo de $30 \%$ (IBGE, 2015).

A preponderância do apoio a "festas, celebrações e manifestações tradicionais e populares" aparece como marcante e está presente nos municípios de diferentes portes populacionais $^{10}$. Pode-se propor a hipótese de que os municípios, como entes locais, estabelecem relações de maior valorização das culturas locais. Nesse sentido, o apoio financeiro público pode demonstrar um reconhecimento pelas gestões do valor cultural, a ponto de se configurar como digna de apoio público. Mas a predominância pode apontar para uma atuação pontual e sem continuidade durante os momentos não festivos do

\footnotetext{
${ }^{10}$ Variando de $75,78 \%$ nos municípios menores, de até 5 mil habitantes, a $82,05 \%$ nos municípios de mais de 500 mil habitantes, e atingindo seu maior percentual, de $87,36 \%$, na faixa populacional entre 100 e 500 mil habitantes (IBGE, 2015).
}

ano. A grande presença dos "Eventos" também chama atenção. O percentual de municípios que afirmaram apoiar a atividade teve um crescimento de quase 15 pontos percentuais de 2014 para 2018 , sendo ela a única atividade com crescimento significativo no período (IBGE, 2015 e 2019). Sintomático o crescimento em um momento de ataque às políticas culturais federais e à cultura.

A forte presença dos três tipos de manifestações culturais principalmente apoiadas pode sugerir uma tendência preocupante: a concentração do fomento cultural em atividades eventuais em detrimento de uma maior atenção aos fazeres e aos processos de produção cultural, tornando a atuação da gestão cultural ocasional e dispersa, sem horizontes mais continuados. Outro dado, que parece reforçar tal interpretação, indica que $40,81 \%$ das gestões municipais afirmam possuir um calendário de festividades e/ou eventos como parte de uma ação de promoção do turismo cultural (IBGE, 2015). Ainda que o calendário de atividades turísticoculturais possa desempenhar papel importante para a atração, imagem e economia da cidade, ele pode 
RUBIM, Antonio Albino C.; ALMEIDA, Juliana; METTENHEIM, Sofia. Federalismo e políticas municipais de financiamento à cultura no Brasil. PragMATIZES - Revista Latino-Americana de Estudos em Cultura, Niterói/RJ, Ano 11, n. 20, p. 300-326, março 2021.

submeter a cultura a uma lógica estritamente turística, com todos os problemas daí decorrentes.

A tendência à "eventização" da atuação cultural municipal, como sua redução à produção de atividades meramente ocasionais, corrói a própria ideia de política cultural, que supõe articulação, continuidade e sistematicidade da intervenção cultural. Ela transforma e debilita a intervenção cultural da gestão municipal em ações dispersas e sem nenhuma integração (RUBIM, 2014). Ao considerar a centralidade desses tipos de fomento à cultura, vale considerar alguns pontos elencados por Rafael Andrade (2016, p. 17):

Tendo participado, nos últimos anos, de debates, seminários e congressos dedicados às políticas culturais, não raramente me deparei com uma questão que sempre pareceu bem estabelecida entre os debatedores ali presentes: organização de festa não é política cultural. Há razão nessa afirmação (...)Mas há sempre uma perigosa tendência à generalização.

Talvez os próprios gestores culturais municipais estejam de acordo com a crítica de Andrade (2016), pois pelo menos $30 \%$ dos municípios, que negam ter política cultural, afirmam apoiar financeiramente eventos. Ou talvez eles tenham uma compreensão mais precisa do que são políticas

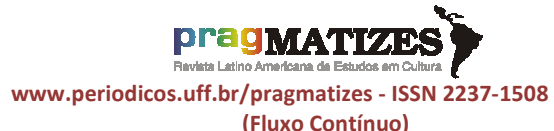

(Fluxo Contínuo)

culturais. O apoio às festas e eventos similares ocupam lugar relevante para a vida e a gestão municipal. Melhor que negá-los como momento possível de políticas culturais, é trabalhar para construir efetivas políticas culturais que acolham as festas e manifestações semelhantes (RUBIM, 2014 , p. 227-229).

Um último dado importante para completar este breve panorama do fomento à cultura municipal se refere aos meios utilizados pela gestão municipal para fomentar iniciativas da sociedade na área da cultura. Os mecanismos mais citados foram o "Prêmio", utilizado por 26,16\% dos municípios e o "Convênio", por 18,56\% (IBGE, 2015). Os demais mecanismos, "Bolsa", "Incentivo fiscal" e "Fundo de Investimento" aparecem com percentuais abaixo de $4 \%$, apesar de terem presença mais significativa nos municípios com mais de 500 mil habitantes. Chama atenção também a relevância da resposta "Outros", com percentual de $21,65 \%$, indicando a utilização de mecanismos diferentes dos listados pelos municípios ou mesmo a presença de velhas maneiras informais e clientelistas de repasse de recursos (IBGE, 2015). 
RUBIM, Antonio Albino C.; ALMEIDA, Juliana; METTENHEIM, Sofia. Federalismo e políticas municipais de financiamento à cultura no Brasil. PragMATIZES - Revista Latino-Americana de Estudos em Cultura, Niterói/RJ, Ano 11, n. 20, p. 300-326, março 2021.

As avaliações de políticas culturais têm desenvolvido perspectivas críticas sobre os mecanismos de fomento mais utilizado pelos municípios, apontando os efeitos que estes têm gerado na rede produtiva da cultura. $\mathrm{O}$ balanço realizado por Luciana Lima e Pablo Ortellado (2013) sobre os diferentes paradigmas de fomento à cultura no país, intitulado "Da Compra de Produtos e Serviços Culturais ao Direito de Produzir Cultura: Análise de um Paradigma Emergente", sistematiza bem as principais questões em torno de cada mecanismo.

A modalidade de prêmio tem sido aplicada a uma variedade de situações diferenciadas de fomento, seja como um valor a ser repassado após concurso, seja como financiamento para execução de ações e projetos culturais, seja como pagamento pela realização de apresentações e manifestações culturais. Sua utilização tende a contemplar uma lógica de apoio à produtos culturais já acabados, mas também pode buscar a simplificação dos procedimentos de prestação de contas por parte dos agentes culturais (LIMA; ORTELLADO, 2013, p. 374).

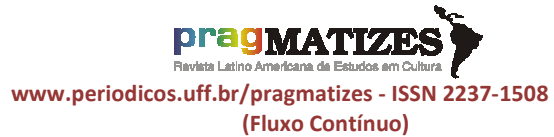

Essa ampla utilização do mecanismo, por sua vez, pode acarretar cenários de insegurança jurídica,pois o prêmio termina por ser aplicado em circunstâncias com lógicas distintas do entendimento comum de premiação.

Em relação à utilização de convênios para repasses de recursos, o debate decorreu, em especial,da avaliação do Programa Cultura Viva. Instrumento jurídico desenhado para repasses de recursos entre unidades federativas, a utilização do mecanismo para fomentar atividades de agentes culturais da sociedade civil resultou na aplicação de exigências administrativoburocráticas de alta complexidade, gerando enormes dificuldades na prestação de contas dos recursos públicos recebidos (LIMA; ORTELLADO, 2013, p. 364). Sua utilização, além de possuir uma inadequação jurídica, comprovou sua incompatibilidade para tratar com esses agentes culturais.

Ao apreciar os problemas dos principais meios utilizados pelos municípios para fomentar iniciativas culturais, têm-se um retrato da ausência de bases jurídicas e administrativas adequadas ao campo cultural, alargado pela utilização do 
RUBIM, Antonio Albino C.; ALMEIDA, Juliana; METTENHEIM, Sofia. Federalismo e políticas municipais de financiamento à cultura no Brasil. PragMATIZES - Revista Latino-Americana de Estudos em Cultura, Niterói/RJ, Ano 11, n. 20, p. 300-326, março 2021.

conceito ampliado de cultura, desde a gestão Gilberto Gil. Importantes avanços foram as legislações aprovadas referentes ao Marco Regulatório de Organizações da Sociedade Civil (MROSC), Lei $\mathrm{n}^{\circ}$ 13.019, de 2014 (BRASIL, 2014b) e a Política Nacional de Cultura Viva, instituída pela Lei $\mathrm{n}^{\circ} 13.018$, de 2014 (BRASIL, 2014a), mas seu reflexo na aplicação municipal depende de processos de regulamentação locais e na disposição dos governos federal e estaduais de buscarem sua efetiva utilização.

\section{Observações finais}

Nas décadas finais do século XX, com o país submetido a governos nacionais de perfil conservador e/ou neoliberal, a resistência protagonizada por municípios administrados por forças democráticas e de esquerda se tornou fundamental para a construção de novas e inovadoras alternativas de políticas públicas. A formulação da proposta do orçamento participativo na cidade de Porto Alegre emerge como um exemplo emblemático, mas não único, das novidades inscritas no cenário político nacional. Algo similar aconteceu no campo cultural. Entre o

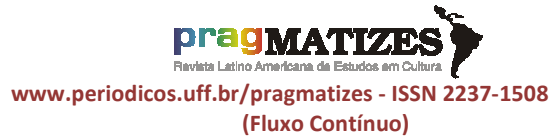

final dos anos 80 do século $X X$ e o início do século XXI, muitos Estados e Municípios criam inventivas políticas culturais, acumulando experiências que irão permitir a formulação das avançadas propostas, que caracterizam mais adiante a gestão Gilberto Gil. Márcio Meira, como anotado antes, analisa algumas dessas gestões político-culturais e sua continuidade, certamente não linear, mas plena de tensões, avanços e recuos, com seus ricos desdobramentos posteriores (MEIRA, 2018).

O Brasil vive hoje circunstância dramática desde o golpe midiáticojurídico-parlamentar de 2016, que destituiu a presidenta Dilma Rousseff e feriu a democracia no país. A situação se agravou com os processos antidemocráticos presentes na eleição presidencial de 2018, como o afastamento ilegítimo do candidato, que estava à frente de todas as pesquisas eleitorais, e com a "vitória" da extrema-direita. Desde a posse de Messias Bolsonaro o panorama político, social, econômico, ambiental e cultural no Brasil tem se deteriorado, bem como sua presença no cenário internacional. 
RUBIM, Antonio Albino C.; ALMEIDA, Juliana; METTENHEIM, Sofia. Federalismo e políticas municipais de financiamento à cultura no Brasil. PragMATIZES - Revista Latino-Americana de Estudos em Cultura, Niterói/RJ, Ano 11, n. 20, p. 300-326, março 2021.

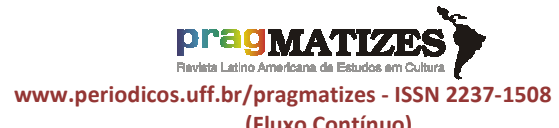

(Fluxo Contínuo)
A pandemia do coronavírus, com seu irresponsável enfrentamento pela gestão federal, aumentou ainda mais o pandemônio em que sobrevive - Brasil. O campo da cultura, como assinalado, tem sido profundamente afetado: pela paralisia das políticas públicas de cultura; pela destruição das políticas culturais desenvolvidas nos governos petistas; pela imposição da censura e agressão às liberdades de criação e expressão e pela asfixia financeira da cultura. Nesse contexto, as iniciativas de parlamentares do poder legislativo nacional e a mobilização do campo cultural tem sido barreiras de contenção ao desmonte cultural. A Lei Aldir Blanc, de apoio a ações emergenciais ao setor cultural, atingido pela pandemia, é um claro exemplo disso. Sintoma das inúmeras desconfianças que orbitam na gestão federal, a lei privilegia o repasse dos recursos da cultura para a execução de estados e municípios.

Nesta complexa e difícil conjuntura e levando em conta a imensa diversidade cultural e territorial brasileira, o estudo das modalidades de fomento dos governos municipais ganha sentido. A partir das estatísticas e apontamentos apresentados neste texto, buscou-se traçar um breve panorama de como se organizam as políticas de fomento à cultura nos municípios. Fica evidente uma crescente institucionalização das instâncias gestoras locais da cultura, embora sujeita aos avanços e retrocessos. Essa institucionalidade, maior organização e valorização da gestão cultural no âmbito local se torna fundamental para possibilitara atuação dos municípios nesse momento de crise. Para o repasse dos recursos federais derivados da Lei Aldir Blanc, por exemplo, será exigida capacidade institucional nos municípios para operacionalizar $\mathrm{o}$ recebimento e a distribuição do apoio emergencial aos elos de maior vulnerabilidade na teia cultural. Sem gestões municipais atuantes, conectadas com o território e estruturadas, é difícil imaginar uma política cultural que consiga se fazer presente nesse contexto.

A centralidade das festividades e dos eventos nos governos locais, assim como as culturas tradicionais e populares, aponta a necessidade de considerar esse dado, histórico e complexo, para pensar políticas culturais. As celebrações, que 
RUBIM, Antonio Albino C.; ALMEIDA, Juliana; METTENHEIM, Sofia. Federalismo e políticas municipais de financiamento à cultura no Brasil. PragMATIZES - Revista Latino-Americana de Estudos em Cultura, Niterói/RJ, Ano 11, n. 20, p. 300-326, março 2021.

possuem relação íntima com identidades locais, podem ser agenciadas para catalisar processos de transformação, desenvolvimento e mobilizações municipais. Tal relação se apresenta quase como uma competência inalienável dos governos locais no entendimento de cultura e políticas culturais. Entretanto, o papel da política cultural deve ir além disso.

A disparidade regional, presente em todos os dados levantados, aponta a concentração de capacidades institucionais, recursos e presença de políticas culturais nas cidades maiores. Embora siga tendências da gestão pública como um todo, ela reforça a necessidade de uma investigação mais aprofundada da gestão cultural nos pequenos e médios municípios brasileiros. Modelos que consideram características próprias desses municípios ganham proeminência no debate, tratando de desigualdades sociais e territoriais profundas e propondo saídas interessantes para subvertê-las. Entretanto, pouco se sabe sobre políticas culturais de pequenos e médios municípios.

Olhar para as propostas municipais de fomento à cultura, com novidades e redundâncias, pode

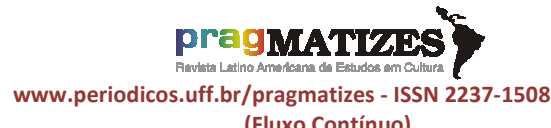

(Fluxo Contínuo)

apontar nessa cruel conjuntura brasileira atual para modalidades novas de resistência e de alternativas para a construção cidadã de mecanismos de apoio à cultura, dimensão essencial para a reconstrução do país, em uma perspectiva democrática, soberana, justa e criativa. O município em uma estrutura federativa pode ser relevante âmbito de resistência e de inovação em todas as dimensões da sociedade e, muito especialmente, na cultura. $O$ ano de 2020, que passará à história e à vida de todos como ano do coronavírus e da quarentena, comporta também eleições municipais no Brasil. Elas podem ser um passo para a democratização do Brasil.

\section{Referências bibliográficas}

ABRUCIO, Fernando Luiz. A coordenação federativa no Brasil: a experiência do período $\mathrm{FHC}$ e os desafios do governo Lula. Revista Sociologia Política, Curitiba, $\mathrm{n}^{\circ} 24, \mathrm{p}$. 41-67, jun. 2005.

ALMEIDA, Armando; PAIVA NETO, Carlos Beyrodt. Fomento à cultura no Brasil: Desafios e oportunidades. Políticas Culturais em Revista, Salvador, v. 10, n. 2, p. 35-58, 2017.

ANDRADE, Rafael Moura. A gestão pública do Carnaval do Recife. Políticas Culturais em Revista, 
RUBIM, Antonio Albino C.; ALMEIDA, Juliana; METTENHEIM, Sofia. Federalismo e políticas municipais de financiamento à cultura no Brasil. PragMATIZES - Revista Latino-Americana de Estudos em Cultura, Niterói/RJ, Ano 11, n. 20, p. 300-326, março 2021.

Salvador, v. $9, \mathrm{n}^{\circ} 1$, p. 244-267, jan./jun. 2016.

BARBALHO, Alexandre; BARROS, José Márcio; CALABRE, Lia (orgs.). Federalismo e políticas culturais no Brasil. Salvador: Editora da UFBA, 2013.

BARON, Lia. Fomento às expressões culturais dos territórios periféricos: algumas experiências brasileiras. In: CALABRE, Lia; DOMINGUES, Alexandre. Estudos sobre políticas culturais e gestão da cultura: Análises do campo da produção acadêmica e de práticas de gestão. Rio de Janeiro: Fundação Casa de Rui Barbosa, 2019. p. 237-251.

BARROS, José Márcio. Diversidade cultural e gestão: sua extensão e complexidade. In: BARROS, José Márcio Barros; OLIVEIRA JUNIOR, José (orgs.) Pensar e Agir com a Cultura: desafios da gestão cultural. Belo Horizonte: Observatório da Diversidade Cultural, 2011.

BLANCO, Ismael; GOMÀ, Ricard; SUBIRATS, Joan. El nuevo municipalismo: derecho a laciudad y comunes urbanos. Gestión y Análisis de Políticas Públicas, , Instituto Nacional de Administración Pública (INAP), núm. 20, p. 14-28, 2018.

BRASIL. Instrução Normativa $n^{\circ} 2$, de 23 de Abril de 2019. Estabelece procedimentos para apresentação, recebimento, análise, homologação, execução, acompanhamento, prestação de contas e avaliação de resultados de projetos culturais financiados por meio do mecanismo de Incentivo Fiscal do Programa Nacional de Apoio à Cultura (Pronac). Diário Oficial da União, Brasília, p. 3, 23 abr. 2019.

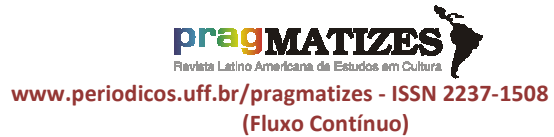

BRASIL. Lei N ${ }^{\circ} 13.018$, de 22 de Julho de 2014. Institui a Política Nacional de Cultura Viva e dá outras providências. Diário Oficial da União, Brasília, 2014a.

BRASIL. Lei $N^{\circ} 13.019$, de $31 \mathrm{DE}$ Julho de 2014. Estabelece o regime jurídico das parcerias entre a administração pública e as organizações da sociedade civil. Diário Oficial da União, Brasília, 2014b.

BRITTO, Neusa Hafner. Planos municipais de cultura. Guia de elaboração. Salvador: Escola de Administração da UFBA, 2017.

COSTA, Rodrigo Vieira. A dimensão constitucional do patrimônio cultural. Rio de Janeiro: Lumen Juris, 2011.

CUNHA FILHO, Francisco Humberto; RIBEIRO, Sabrina Florêncio. Federalismo cultural: significados para a cultura. In: BARBALHO, Alexandre; BARROS, José Márcio; CALABRE, Lia (orgs.). Federalismo e políticas culturais no Brasil. Salvador: EDUFBA, 2013. p.13-41.

CUNHA FILHO, Francisco Humberto. Federalismo Cultural e Sistema Nacional de Cultura. Contribuição ao debate. Fortaleza: Edições UFC, 2010.

FARAH, Marta Ferreira Santos. Inovação e governo local no Brasil contemporâneo. In: JACOBI, Pedro; PINHO, José Antonio (org.). Inovação no campo da gestão pública local: novos desafios, novos patamares. Rio de Janeiro: Editora FGV, 2006. p. 4177.

GALEGO, Esther Solano; ORTELLADO, Pablo; MORETO, Márcio. Guerras culturais e o populismo antipetista nas ruas de 2017. Revista Friedrich Ebert Stiftung Brasil, São Paulo, n¹0, 2017. 
RUBIM, Antonio Albino C.; ALMEIDA, Juliana; METTENHEIM, Sofia. Federalismo e políticas municipais de financiamento à cultura no Brasil. PragMATIZES - Revista Latino-Americana de Estudos em Cultura, Niterói/RJ, Ano 11, n. 20, p. 300-326, março 2021.

GUIMARÃES, Fabiana; SILVA, Raiany. Estudos sobre financiamento e fomento à cultura nos estados e Distrito Federal. In: RUBIM, Antonio Albino Canelas; VASCONCELOS, Fernanda

Pimenta (org.). Financiamento e fomento à cultura no Brasil: estados e distrito federal. Salvador: EDUFBA, 2017. p. 63-98.

INSTITUTO BRASILEIRO DE GEOGRAFIA ESTATÍSTICA. IBGE. Censo Demográfico 2010: Resultados gerais da amostra. Rio de Janeiro: IBGE, 2012. Disponível em: https://biblioteca.ibge.gov.br/visualizac ao/periodicos/99/cd_2010_resultados_ gerais_amostra.pdf. Acesso: jul. 2020.

INSTITUTO BRASILEIRO DE GEOGRAFIA ESTATÍSTICA. IBGE. Pesquisa de Informações Básicas Municipais: Perfil dos Municípios Brasileiros (Cultura, 2006). Rio de Janeiro: IBGE, 2007. Disponível em: https://www.ibge.gov.br/estatisticas/so ciais/educacao/10586-pesquisa-deinformacoes-basicas-

municipais. $h t m l ?=\& t=0-q u e-e . \quad$ Acesso em: jul. 2020.

INSTITUTO BRASILEIRO DE GEOGRAFIA ESTATÍSTICA. IBGE. Pesquisa de Informações Básicas Municipais: Perfil dos Municípios Brasileiros (Cultura, 2014). Rio de Janeiro: IBGE, 2015. Disponível em: https://www.ibge.gov.br/estatisticas/so ciais/educacao/10586-pesquisa-deinformacoes-basicas-

municipais. $h t m l ?=\& t=0-q u e-e . \quad$ Acesso em: jul. 2020.

INSTITUTO BRASILEIRO DE GEOGRAFIA ESTATÍSTICA. IBGE. Pesquisa de Informações Básicas Municipais: Perfil dos Municípios Brasileiros. Rio de Janeiro: IBGE, 2019. Disponível em:

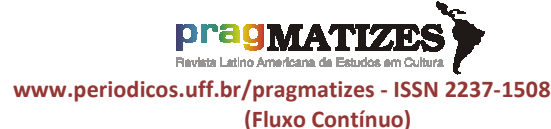

(Fluxo Contínuo)

https://www.ibge.gov.br/estatisticas/so ciais/educacao/10586-pesquisa-deinformacoes-basicasmunicipais.html $?=\& \mathrm{t}=0$-que-e. Acesso em: jul. 2020.

LIMA, Luciana; ORTELLADO, Pablo. Da Compra de Produtos e Serviços Culturais ao Direito de Produzir Cultura: Análise de um Paradigma Emergente. Dados - Revista de Ciências Sociais. Rio de Janeiro, vol. 56, n 2, 2013.

MEIRA, Márcio. Gestão cultural no Brasil: uma leitura do processo de construção democrática. In: RUBIM, Antonio Albino Canelas (org.). Política cultural e gestão democrática no Brasil. São Paulo: Fundação Perseu Abramo, 2016. p.17-36.

MINISTÉRIO DA CULTURA. Estruturação, institucionalização e implementação do Sistema Nacional de Cultura (SNC). Brasília, Ministério da Cultura, 2011.

OLIVEIRA, Maria Carolina Vasconcelos. Políticas para as artes: reflexões gerais e alguns tópicos do debate paulistano. In: SIMIS, Anita; NUSSBAUMER, Gisele; FERREIRA, Kennedy Piau. (orgs.). Políticas para as artes. Salvador: EDUFBA, 2018. p. 33-64.

PAIVA NETO, Carlos Beyrodt. Modelo federal de financiamento e fomento à cultura. In: RUBIM, Antonio Albino Canelas; VASCONCELOS, Fernanda Pimenta (org.). Financiamento e fomento à cultura no Brasil: estados e distrito federal. Salvador: EDUFBA, 2017. p. 15-62.

PINTO, Luiz Felipe; GIOVANELLA, Ligia. Do Programa à Estratégia Saúde da Família: expansão do acesso e redução das internações por condições sensíveis à atenção básica 
RUBIM, Antonio Albino C.; ALMEIDA, Juliana; METTENHEIM, Sofia. Federalismo e políticas municipais de financiamento à cultura no Brasil. PragMATIZES - Revista Latino-Americana de Estudos em Cultura, Niterói/RJ, Ano 11, n. 20, p. 300-326, março 2021.

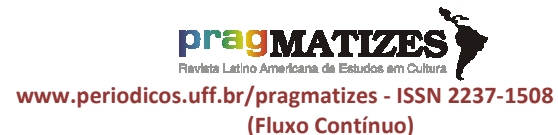

(Fluxo Contínuo)
(ICSAB). Ciênc. saúde coletiva, Rio de Janeiro, v. 23, n. 6, p. 1903-1914, junho 2018.

ROCHA, Sophia Cardoso. Da imaginação à constituição: a trajetória do Sistema Nacional de Cultura de 2002 a 2016. Tese (Doutorado em Cultura e Sociedade). Universidade Federal da Bahia, Salvador, 2018.

RUBIM, Antonio Albino Canelas; PAIVA NETO, Carlos Beyrodt. Panorama do financiamento e fomento à cultura: estados e distrito federal. In: RUBIM, Antonio Albino Canelas; VASCONCELOS, Fernanda Pimenta (org.). Financiamento e fomento à cultura no Brasil: estados e distrito federal. Salvador: EDUFBA, 2017. p. 99-178.

RUBIM, Antonio Albino Canelas. Atuação político-cultural da gestão Messias Bolsonaro. Salvador, 2020 (texto inédito)

RUBIM, Antonio Albino Canelas. La contemporaneidad como edad-media. In: LOPES, Maria Immacolata Vassalo de; NAVARRO, Raúl Fuentes (orgs.). Comunicación. Campo y objeto de estudio. México: Instituto Tecnológico y de Estudios Superiores de Occidente (ITESO) / Universidad Autónoma de Aguascalientes /Universidad de Colima / Universidad de Guadalajara, 2001. p.169-181.

RUBIM, Antonio Albino Canelas. Políticas culturais na Bahia contemporânea. Salvador: EDUFBA, 2014. [em especial Eventos e políticas culturais, p. 58-63 e Políticas culturais e festas, p. 227-229]

RUBIM, Antonio Albino Canelas. Políticas culturais no Brasil: Tristes tradições, enormes desafios. In: RUBIM, Antonio Albino C.; BARBALHO, Alexandre (orgs.).
Políticas Culturais no Brasil. Salvador: EDUFBA, 2007. p. 12-36.

RUBIM, Antonio Albino Canelas. Teses sobre financiamento e fomento à cultura no Brasil. In: VALIATI, Leandro; MOLIER, Gustavo (orgs.). Economia criativa, cultura e políticas públicas. Porto Alegre, Editora da UFGRS/CEGOV, 2016. p.267-278.

SERPA, A. Fala Periferia! In: SERPA, Ângelo (org.). Fala Periferia! Uma reflexão sobre a produção do espaço periférico metropolitano. Salvador: UFBA, 2001. p. 11-14.

SILVA, Maria Ozanira da Silva; YAZBEK, Maria Carmelita; GIOVANNI, Geraldo Di. A política social brasileira no século XXI: a prevalência dos programas de transferência de renda. São Paulo: Cortez, 2008.

SPINK, Peter. Inovação na perspectiva dos inovadores: a experiência do Programa Gestão Pública e Cidadania. Cad. EBAPE.BR, Rio de Janeiro, v. 1, n. 2, p. 01-13, Dec. 2003.

UNGER, Roberto Mangabeira. A constituição do experimentalismo democrático. Revista de Direito Administrativo. Rio de Janeiro, v. 257, p. 57-72, mai. 2011. 